\title{
BMJ Open Three contaminated sites in southern Italy. The Neonatal Environment and Health Outcomes cohort: protocol for a longitudinal birth cohort study
}

\author{
Silvia Ruggieri, ${ }^{1}$ Gaspare Drago, ${ }^{1}$ Paolo Colombo, ${ }^{1}$ Alessio Alesci, ${ }^{1,2}$ \\ Pasquale Augello, ${ }^{1,3}$ Alessandro Bisbano, ${ }^{4}$ Antonino Bucolo, ${ }^{3}$ Patrizia Dattoli, ${ }^{4}$ \\ Raffaella De Sole, ${ }^{4}$ Valentina La Runa, ${ }^{1,5}$ Angela Lopez, ${ }^{4}$ Lucia Lo Presti, ${ }^{5}$ \\ Bruno Magliarditi, ${ }^{2}$ Francesco Paravati, ${ }^{4}$ Giuseppe Pirillo, ${ }^{4}$ \\ Antonino Ziino Colanino, ${ }^{6}$ Fabio Cibella ${ }^{1}$
}

To cite: Ruggieri S, Drago G, Colombo P, et al. Three contaminated sites in southern Italy. The Neonatal Environment and Health Outcomes cohort: protocol for a longitudinal birth cohort study. BMJ Open 2019;9:e029471. doi:10.1136/ bmjopen-2019-029471

- Prepublication history for this paper is available online. To view these files, please visit the journal online (http://dx.doi. org/10.1136/bmjopen-2019029471).

SR and GD contributed equally.

Received 28 January 2019

Revised 3 May 2019

Accepted 9 May 2019

Check for updates

(C) Author(s) (or their employer(s)) 2019. Re-use permitted under CC BY-NC. No commercial re-use. See rights and permissions. Published by BMJ.

For numbered affiliations see end of article.

Correspondence to

Dr Fabio Cibella;

fabio.cibella@ibim.cnr.it

\section{ABSTRACT}

Introduction Exposure to environmental contaminants during pregnancy is one of the determinants of child's future health outcomes. The effect of environmental pollution on pregnant women living in heavily polluted areas is of special interest and, in this context, the Neonatal Environment and Health Outcomes (NEHO) cohort will focus on the investigation of (1) toxicants transferred from the environment to the mother and from the mother to the developing fetus and (2) the influence of toxicants on pregnancy outcomes, fetal development and health status during infancy. Because the human placenta is positioned at the interface between the maternal/external environment and the embryo, it can be considered a highly informative matrix regarding many key pregnancy events that can shape infant's future health. Methods and analysis The NEHO cohort will enrol an estimated total of 800 pregnant women in three selected National Priority Contaminated Sites in southern Italy. Epidemiological data, concerning maternal health status, lifestyle and pregnancy, are obtained through questionnaires provided to the mother starting from the last 2 months of pregnancy. At delivery, maternal blood, umbilical cord blood and placenta tissue are collected to assess contaminant levels and to clarify how toxicants interact with the placental domain. Furthermore, placental transcriptome is studied in order to explore the interferences of toxicants on the role of the placenta in maternal/fetal interplay. Regular follow-up is planned at 6, 12 and 24 months.

Ethics and dissemination The study has been approved by all the Ethics Committees of the three National Priority Contaminated Sites involved: the Ethics Committee of the University Hospitals of Messina (18 September 2017, n. 9/2017); the Ethics Committee 'Catania 2' (11 July 2017, n. 38/2017/CECT2); the Ethics Committee of the Region of Calabria (20 July 2017, n. 173). Findings will be disseminated in the scientific community and on a regional basis for appropriate policy actions.

\section{INTRODUCTION}

Early life exposure to factors such as environmental pollutants, dietary habits and parental
Strengths and limitations of this study

- The Neonatal Environment and Health Outcomes (NEHO) cohort is a birth cohort study which, for the first time in Italy, is specifically aimed at evaluating the environment/health relationship in heavily polluted areas.

- In the context of the NEHO, cohort exposure is assessed by means of the biomonitoring of pollutants in biological samples from mother and child, along with an extensive and multidisciplinary evaluation of pollution in all environmental matrices, including the food chain.

- NEHO enrols mother-child pairs residing in disadvantaged areas of low socioeconomic status, thus representing a peculiar condition in the context of Italian and European birth cohorts.

- The NEHO cohort requires voluntary participation, which could constitute a bias due to the self-selection of enroled women.

- The enrolment is limited to the catchment areas of public hospitals.

lifestyles may affect growth and development during fetal life and childhood as well as influence health over a person's entire lifetime. ${ }^{1}$ Early childhood is particularly important as it is a period which involves contact with factors that may affect many outcomes in later life. ${ }^{2}$ Consequently, epidemiological studies on the health effects of environmental pollution typically focus on the most vulnerable subjects; thus, in recent years, considerable effort has been made to evaluate the possible effects of environmental contaminants on children's health.

From Barker's postulate of the 'intrauterine origins of health and disease susceptibility, ${ }^{34}$ growing evidence has highlighted how the early stage of fetal development can 
alter the health trajectory throughout life.$^{5-8}$ This provides a better understanding of the causes of many multifactorial disorders. In fact, adult diseases may have an in utero origin, when suboptimal intrauterine conditionsincluding exposure to environmental contaminantsinduce irreversible changes that manifest themselves in postnatal and adult life. Birth cohorts provide an opportunity to monitor and study associations between early life environmental exposures and child development and health. ${ }^{9}$ By means of a long-term follow-up, cohorts help to evaluate the possible effects of exposure to environmental pollutants on the development of adult diseases, also allowing the identification of risk factors, taking into account genetics, epigenetics, socioeconomic factors and lifestyles.

The number of studies linking maternal exposure to environmental pollutants during fetal gestation to various adult health outcomes has been gradually increasing. Several Italian pregnancy and birth cohort studies have investigated the health effects of environmental contaminant exposure during early life, with specific attention to prenatal exposures, air pollution, growth, neurocognitive development and respiratory health: NINFEA cohort, ${ }^{10}$ NACII,${ }^{11}$ MUBICOS, ${ }^{12}$ Piccolipiù, ${ }^{13}$ GASPII and Co.N.ER. ${ }^{14}$ and Mamma \& Bambino. ${ }^{15}$

Epidemiological evidence supports the concept that exposure to pollutants during early life-as measured during pregnancy and/or childhood-has a detrimental impact on the health outcomes of the child. Previous works indicate that polybrominated diphenyl ethers (PBDEs) and polychlorinated biphenyls (PCBs) bioaccumulate in human placenta tissue, possibly contributing to prenatal exposures to environmental contaminants. ${ }^{16-18}$ PBDEs-largely used as flame retardants in electronic equipment, carpets and in polyurethane foam used in furniture-have been detected in umbilical cord blood. ${ }^{19}{ }^{20}$ Because the human placenta is the interface between the maternal/external environment and the embryo, it can be used as an environmental monitoring system. In fact, placental examination is a useful tool for estimating both maternal and fetal exposures. ${ }^{18} 2122$ Moreover, the placenta plays an active role in the homeostasis of the intrauterine environment and also mediates signal transmission from the fetus to the mother and vice versa. Nutrition supply, endocrine/immune regulation and gas exchange are orchestrated by the placenta. All of this evidence makes the placenta a highly informative organ for the study of pregnancy. ${ }^{23}$

The presence of toxicants in the placenta can cause alterations of its structure and function as well as interfere with fetal development. An example is provided by exposure to cigarette smoking during pregnancy: a modification of the gene expression of placental and fetal cells has been demonstrated in relation to both direct and indirect tobacco smoke exposure. ${ }^{24-26}$ High concentrations of mercury in fetal tissues are associated with the reduction of hormone synthesis and oxygen consumption by the placenta. ${ }^{27} 28$
Persistent organic compounds have been measured in fetal tissues, in particular, in the placenta. Exposure to PCBs and PBDEs has been shown to interfere with fetal development, resulting in significant weight reduction at birth. ${ }^{29}$

Umbilical cord blood and the placenta are also non-invasive indicators for exposure to heavy metals, and may be easily collected along with maternal blood. ${ }^{30}$ The cadmium level in the placenta is also a valuable biomarker of dietary metal exposure related to specific dietary habits and soil characteristics. Lead and mercury have been shown to be easily transferred through the placental and blood barriers. ${ }^{2831}$

Monitoring pollutant concentrations in human tissues, along with the extensive characterisation of the entire environmental matrix proposed in the International Centre of Advanced Study in Environment, Ecosystem and Human Health (CISAS) project will provide new insights into toxicant transfer routes from the environment to the human fetus. Our analysis will be focused on the investigation of toxicants that are transferred from the mother's blood to the developing fetus and on the influence of toxicants on fetal development, pregnancy outcomes and late-onset health consequences. Particular attention will also be paid to the possible interaction between environmental exposures and the low socioeconomic status which often characterises the investigated population.

\section{METHODS AND ANALYSIS \\ Experimental context}

The CISAS project, funded by the Italian Ministry of Education, Universities and Research, aims at understanding the chemical-physical processes that regulate the distribution of contaminants in various environmental matrices and their transfer to the ecosystem and humans. The CISAS Project has been developed for three selected National Priority Contaminated Sites (NPCSs) in southern Italy; in these contexts, the influence of environmental pollution on pregnant women is of special interest.

The three selected NPCSs are Milazzo-Valle del Mela, Augusta-Priolo and Crotone. Those in Milazzo and Augusta are widely industrialised coastal areas located in eastern Sicily in which large production sites are present, including refineries, petrochemical and cement plants, power plants, numerous hazardous waste dumps and the former Eternit plant in Siracusa where asbestos was processed. ${ }^{32}$ In the Crotone area, located in the region of Calabria, the most relevant environmental impact is due to three disused industrial areas (the former Pertusola, Fosfotec and Agricoltura sites) which operated between the 1920s and the 1990s, mainly in the fields of zinc, phosphoric acid and complex fertiliser production. ${ }^{33}$

During the course of the (ongoing) CISAS project, the Neonatal Environment and Health Outcomes birth cohort (NEHO) birth cohort will enrol pregnant women 
living in the three NPCSs, along with pregnant women living in surrounding areas, outside them. The NEHO cohort is aimed at understanding the processes and mechanisms involved in the transfer of heavy metals and Persistent Organic Pollutants (POPs, e.g., PBDEs, PCBs and chlorinated pesticides) from the environment to the ecosystem and humans. In the context of the CISAS project, the same toxicants will be evaluated in all environmental matrices (atmosphere, soil, sediment, inland waters and sea) as well as the food chain (fish, meat, eggs, milk and dairy products, sampled from local producers of each studied area).

\section{Study population and recruitment}

Starting in January 2018, the NEHO cohort began recruiting pregnant women living in the three NPCSs of Crotone, Milazzo-Valle del Mela and Augusta-Priolo, in southern Italy (figure 1), along with pregnant women living in surrounding areas presenting similar geographic and sociodemographic characteristics.

The NEHO study involves 26 cities subdivided into study areas and local reference areas. Table 1 shows the selected cities in Sicily and Calabria, as well as their respective distance from industrial areas.

Local reference areas were identified as 'local controls' by ISTISAN reports ${ }^{32} 34$ and by the SENTIERI Project, a study of the epidemiological evidence of associations between causes of death and environmental exposures ${ }^{3536}$ coordinated by the Italian National Institute of Health and supported by the Ministry of Health. To maximise recruitment efficiency, maternity units were selected in each NPCS on the basis of both the deliveries/population ratio and available resources.
The NEHO cohort recruits pregnant women in four selected maternity units located in the public hospitals of four cities: the 'G. Fogliani' Hospital in Milazzo (for the Milazzo-Valle del Mela NPCS), the General Hospital of Lentini and the 'Umberto I' Hospital in Siracusa (for the Augusta-Priolo NPCS) and the 'San Giovanni di Dio' Hospital in Crotone.

All pregnant women treated at one of the maternity units during the last 2 months of pregnancy are asked to participate-on a voluntary basis-in the study, which means receiving follow-up visits until delivery. Thereafter, the children are followed from birth to 24 months of age to assess their exposure to toxicants through their diet and physical environment, as well as their cognitive and behavioural development. In order to limit possible bias due to the self-selection of enrolled women and exclusive recruitment in public hospitals, we have organised periodic meetings in birthing classes and with general practitioners.

Figure 2 shows the selected cities and the distribution of the hospitals where the pregnant women are recruited in each NPCS.

Because the recruitment of the NEHO cohort is carried out in a heavily polluted area, detailed information is also collected on daily commuting to work, use of electronic devices at home, dietary habits (validated food frequency questionnaires are used), including data on the type of water consumed and the place of fish, meat and vegetable purchases, food packaging, use of plastic dishes, detergents and so on.

After recruitment, mothers are asked to fill out the second part of the baseline questionnaire by means of a

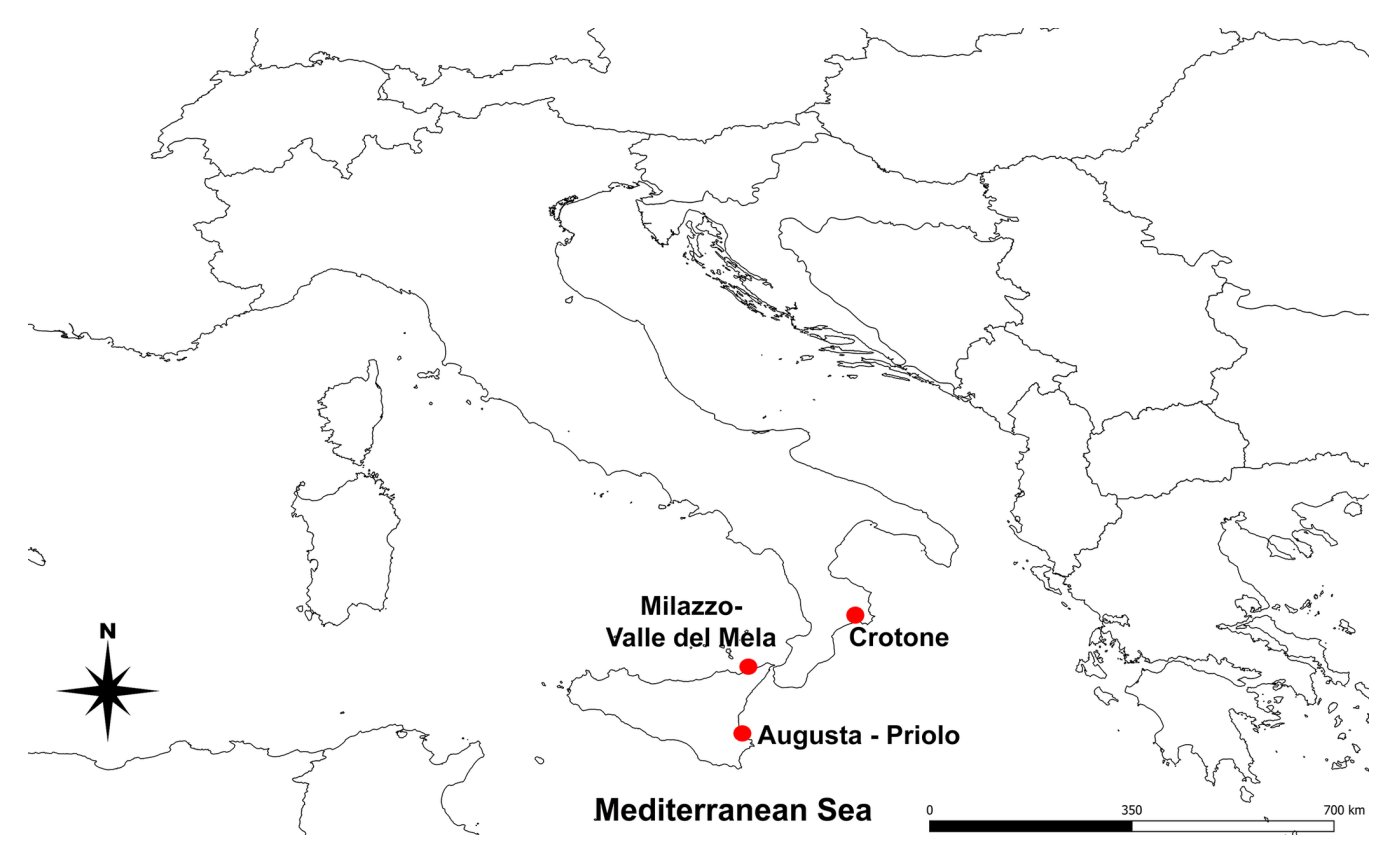

Figure 1 The three selected National Priority Contaminated Sites involved in the study in the south Mediterranean area of Italy. Created through QGIS Development Team, 2009. QGIS Geographic Information System. Open Source Geospatial Foundation. URL http://qgis.org; shapefile from https://www.arcgis.com/home/item.html?id=2ca75003ef9d477fb22db19832c9554f. Last accessed 29 March 2019. 
Table 1 The communities selected for the project in both study and local reference areas, with their respective distance from industrial areas

\begin{tabular}{|c|c|c|c|c|}
\hline \multirow{2}{*}{$\begin{array}{l}\text { National Priority } \\
\text { Contaminated } \\
\text { Sites }\end{array}$} & \multicolumn{2}{|l|}{ Study areas } & \multicolumn{2}{|c|}{$\begin{array}{l}\text { Local reference } \\
\text { areas }\end{array}$} \\
\hline & Name & km & Name & km \\
\hline \multirow[t]{4}{*}{$\begin{array}{l}\text { Milazzo-Valle del } \\
\text { Mela }\end{array}$} & Milazzo & - & $\begin{array}{l}\text { Barcellona } \\
\text { P.d.G. }\end{array}$ & 8 \\
\hline & Pace del Mela & 6 & Spadafora & 13 \\
\hline & $\begin{array}{l}\text { San Filippo del } \\
\text { Mela }\end{array}$ & 5 & $\begin{array}{l}\text { Terme } \\
\text { Vigliatore }\end{array}$ & 12 \\
\hline & & & $\begin{array}{l}\text { Villafranca } \\
\text { Tirrena }\end{array}$ & 22 \\
\hline \multirow[t]{5}{*}{ Augusta-Priolo } & Augusta & 9 & Avola & 27 \\
\hline & Floridia & 8 & $\begin{array}{l}\text { Canicattini } \\
\text { Bagni }\end{array}$ & 19 \\
\hline & Melilli & 5 & Carlentini & 22 \\
\hline & Priolo Gargallo & - & Lentini & 22 \\
\hline & Solarino & 8 & & \\
\hline \multirow[t]{9}{*}{ Crotone } & Crotone & - & Botricello & 28 \\
\hline & & & Cariati & 49 \\
\hline & & & $\begin{array}{l}\text { Crucoli and } \\
\text { local districts }\end{array}$ & 39 \\
\hline & & & Cirò Marina & 32 \\
\hline & & & $\begin{array}{l}\text { Isola di C. } \\
\text { Rizzuto }\end{array}$ & 14 \\
\hline & & & $\begin{array}{l}\text { Melissa and } \\
\text { local districts }\end{array}$ & 26 \\
\hline & & & $\begin{array}{l}\text { S. Leonardo } \\
\text { di Cutro }\end{array}$ & 28 \\
\hline & & & Strongoli & 20 \\
\hline & & & $\begin{array}{l}\text { Marina di } \\
\text { Strongoli }\end{array}$ & 23 \\
\hline
\end{tabular}

web-based interface. The second part includes questions on health status, smoking habits, diet, occupational exposures and any other possible chemical exposures in the periconceptional period.

\section{Inclusion criteria}

The general criteria for combined residential and hospital-based recruitment of healthy pregnant women are as follows:

- Residence in a study area or a local reference area for at least 1 year.

- Ability to speak and understand the Italian language.

- Being 18-40 years old at the time of delivery.

- Notfollowing any programme of assisted reproduction.

- Absence of serious chronic diseases, such as diabetes, hypertension, etc.

- Absence of any evident complications during pregnancy diagnosed previous to signing informed consent.

\section{Questionnaire}

As in previous studies, the NEHO questionnaire collects comprehensive information on pre-pregnancy health status, such as physical activity, lifestyle, stress factors, sociodemographic characteristics, use of medication and information about previous births (including stillbirths). The same data are also collected for the gestational period, along with smoking habits (including e-cigarette use), possible chemical exposures and maternal health characteristics.

Subsequently, after delivery, information is collected on newborns over a 2 -year period regarding use of medicine, nutritional outcomes (including growth and breastfeeding), neurocognitive development, infections and injuries, hospitalisations and characteristics of home environments.

In addition to the above-listed variables, the NEHO cohort collects the following detailed information about diet: the origin of the food (whether local or unknown) and place of purchase (local markets or large supermarket chains), as well as information about drinking water. Information on domestic and/or working environment exposures is also collected.

\section{Collection of biological samples}

Biological material is collected, managed and briefly cryopreserved in the recruiting centres and periodically transferred to the NEHO biobank, located at the Institute of Biomedicine and Molecular Immunology (Palermo, Italy), where it is stored at $-80^{\circ} \mathrm{C}$. All four maternity units follow the same protocol for sample collection, processing and storage. All personnel involved are periodically trained and all protocols are updated at regular intervals.

Blood samples $(15 \mathrm{~mL})$ are drawn from a mother's cubital vein at enrolment and after delivery and from the child's umbilical cord immediately after delivery $(5 \mathrm{~mL}$ in K2-EDTA and $10 \mathrm{~mL}$ in serum separator tubes). Blood tubes are stored at $4^{\circ} \mathrm{C}$ and centrifuged within 24 hours for $10 \mathrm{~min}$ at $2000 \mathrm{xg}$. Serum is divided into eight aliquots of approximately $0.5 \mathrm{~mL}$. Fractionated K2-EDTA blood is dispensed in four aliquots of plasma $(0.5 \mathrm{~mL}$ each $)$. One aliquot of at least $0.1 \mathrm{~mL}$ of white blood cells (buffy coat) is stored in cryotubes.

In addition, 12 placenta samples are systematically collected from central and peripheral regions by means of a biopsy punch, stored in cryotubes with RNAlater and frozen at $-20^{\circ} \mathrm{C}$ within 2 hours of delivery. Cryotubes with maternal and cord blood samples are periodically transported in dry ice to the NEHO biobank where they are stored in $-80^{\circ} \mathrm{C}$ freezers. Placenta samples are also transferred to the central biobank for long-term storage at $-80^{\circ} \mathrm{C}$. Incomplete sample collection is not considered as exclusion criteria for follow-up.

Figure 3 provides a schematic overview of the project's time course.

\section{Biobank}

The long-term perspective of the project and the possibly delayed evidence of children's impairment in physical, psychological, social and cognitive health necessitate the creation of a biobank for the storage of maternal and fetal tissues. 


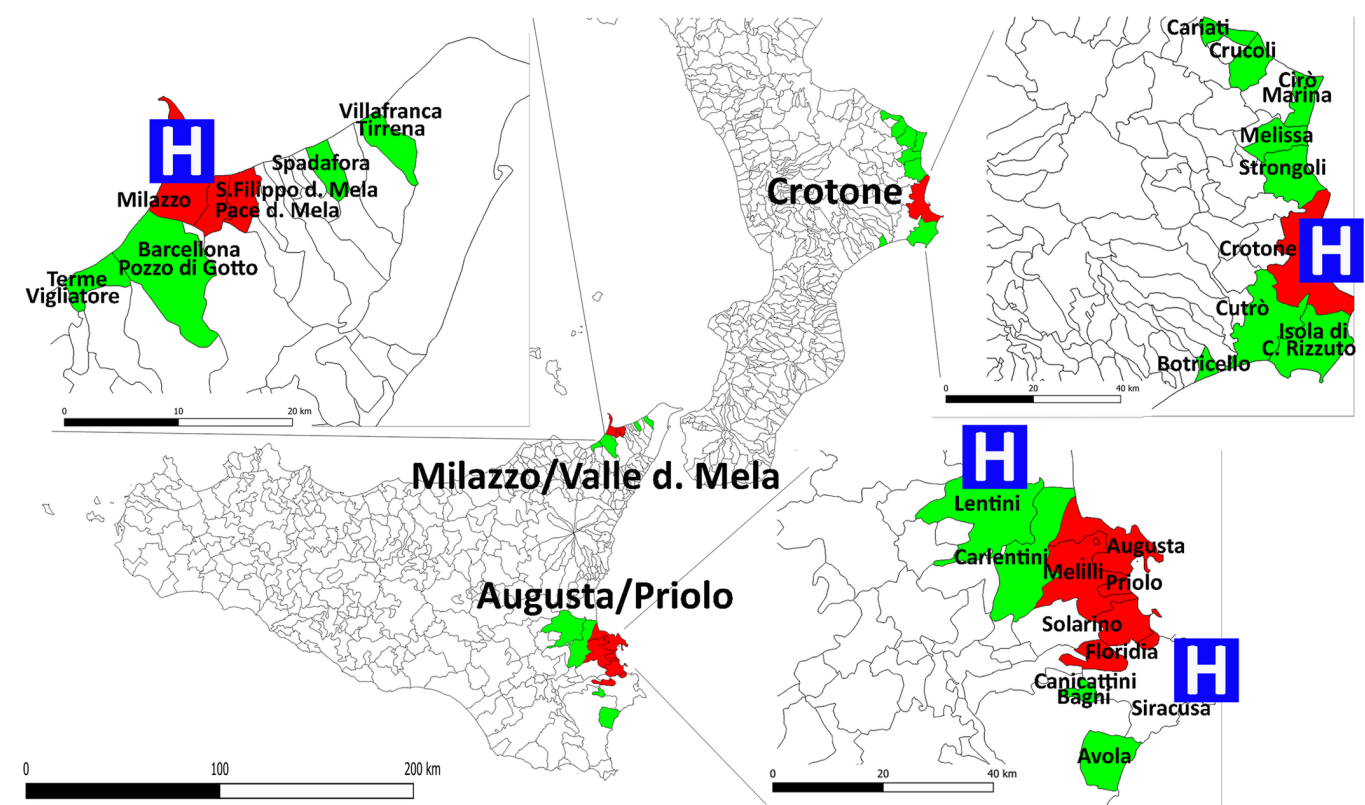

Figure 2 The selected communities and the distribution of the maternal units $(\mathrm{H})$ where the pregnant women are recruited. The National Priority Contaminated Sites are in red, the surrounding areas are in green. Created through QGIS Development Team, 2009. QGIS Geographic Information System. Open Source Geospatial Foundation. URL http://qgis.org; shapefile from https:// www.arcgis.com/home/item.html?id=61145ee86375431f9c54762de4ccd9e7.

The preservation of high-quality placental tissue specimens will enable the search for new biomarkers of prenatal exposure to pollutants as well as promote a better understanding of the mechanisms through which potential disruptors are transmitted from mother to fetus. This may suggest possible interventions to be made during pregnancy for the prevention of some adult diseases.

\section{Transcriptomics}

The placenta has an active role in fetal development. The impairment of placental formation, differentiation and/or function severely affects fetal development and is associated with a wide range of pregnancy complications, including pregnancy loss. ${ }^{37}$ Other complications linked to placental dysfunction, including gestational diabetes, hypertension, pre-eclampsia and intrauterine growth restriction can irreversibly result in greater susceptibility to multifactorial disorders during the entire lifespan. ${ }^{38-40}$ It is known that toxic substances may interfere with placental signalling cascades involved in metabolism, nutrient and waste product transport, and steroid hormone and enzyme production and release. ${ }^{41}$ Therefore, in the context of the NEHO cohort, we will investigate the relationship between exposure to environmental toxic compounds (both heavy metals and POPs) and shifts in gene expression by means of a whole transcriptome analysis. RNA microarray analysis will be performed by SurePrint G3 Human Gene Expression v3 $8 \times 60 \mathrm{k}$ Microarray, acquired by the Agilent G2565CA Microarray scanner. The raw data will be analysed using $\mathrm{R}$ biostatistical computing platform RStudio GUI. Gene set enrichment analysis will be performed to visualise the regulated biological processes.

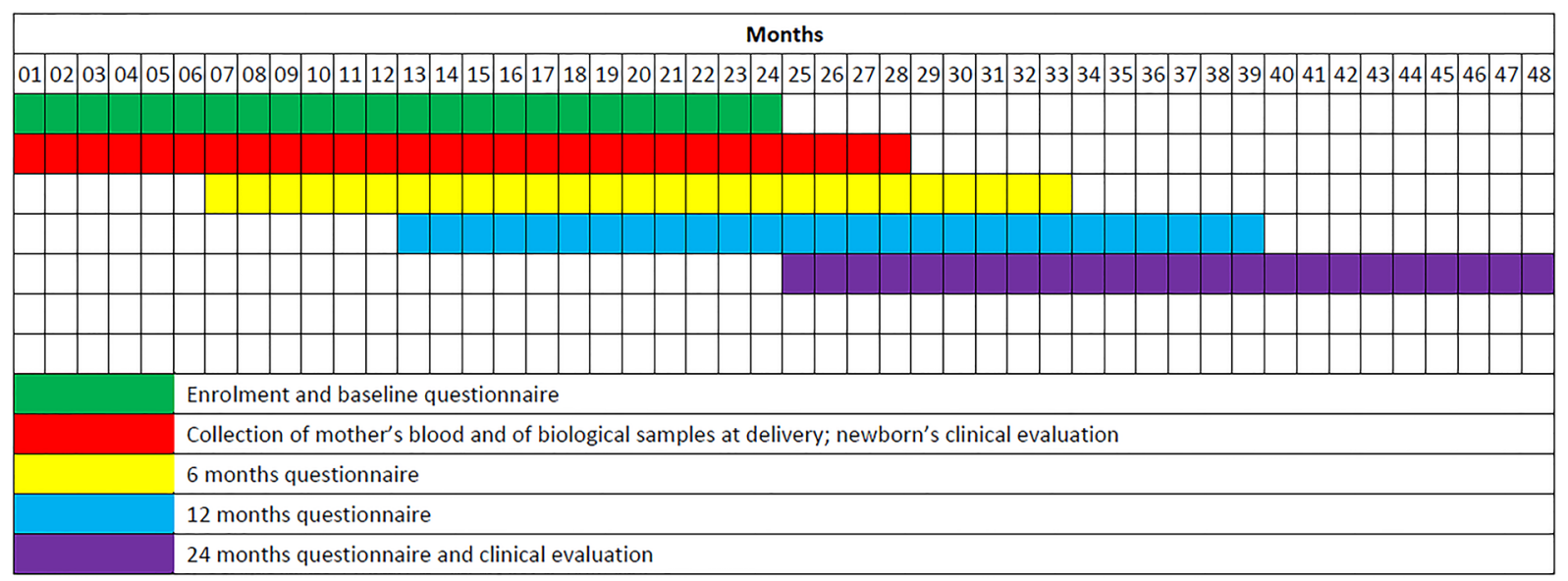

Figure 3 Schematic overview of the project's time course. 


\section{Outcome assessment}

At the time of delivery, a clinical evaluation is performed: delivery details, birth outcomes, infant anthropometry, including birth weight, head circumference and Apgar score at 5 and $10 \mathrm{~min}$ are recorded. The presence of any possible congenital defects is noted for each newborn.

Children are followed up during the first 2years of life through web-administered questionnaires at 6, 12 and 24 months: breastfeeding, nutritional supplements and vaccination data are recorded by regular parental surveys conducted via web.

Similar to the second part of the baseline questionnaire, the follow-up questionnaires (6 and 12 months) are self-administered. If requested, telephone helpline service is provided for those experiencing difficulties in using the online self-administered questionnaires.

Women are regularly contacted by phone or email and are encouraged to follow the timeline for questionnaire submission.

Finally, at 24 months after birth, all participants will be invited to an infant clinical evaluation. A trained psychologist will administer the Bayley-III test, including cognitive, language and motor scales. Physiological and behavioural development will be evaluated by means of the CAT/CLAMS test. ${ }^{42}$

Long-term outcomes will be evaluated by means of regional health records providing information on causes of hospitalisation and death.

All the collected data are organised in a database and undergo a pseudonymisation procedure.

Table 2 shows the major outcomes that will be evaluated in the NEHO cohort.

\section{Statistics}

Primary analyses will concern the evaluation of possible differences in toxicant concentrations in maternal blood, placental tissue and cord blood by exploring correlations between toxicant concentrations in different biological matrices. Moreover, the possible effects of confounders / effect modifiers will be evaluated for each toxicant by means of generalised linear models. Clinical outcomes will be evaluated by means of logistic models (for dichotomous variables) or generalised linear models (for continuous variables). Finally, subsamples of placental specimens will be evaluated for transcriptome analysis.

The NEHO cohort will enrol an estimated total of 800 mother-child pairs from the three highly polluted areas, by January 2021. Sorkun et at ${ }^{43}$ found increased $(0.048 \pm 0.014$ vs $0.038 \pm 0.012)$ cadmium concentration in placentas of Turkish women living in a highly polluted area with respect to women living in a rural control area. ${ }^{43}$ Based on these data, we estimate that a sample of 38 subjects for each study and control area (76 subjects as total sample) will be adequate for detecting such differences in placental heavy metals, with an alpha level of 0.05 and a power (1- $\beta$ ) of 0.95. Moreover, García-Esquinas et $a l^{44}$ found significantly reduced 5-min Apgar scores $(9.13 \pm 0.6$ vs $9.40 \pm 0.5)$ in newborns with umbilical
Table 2 Outcomes of the study, separately for age, with their description

\begin{tabular}{|c|c|c|}
\hline $\begin{array}{l}\text { Project } \\
\text { stage }\end{array}$ & Outcome description & \\
\hline At the birth & $\begin{array}{l}\text { Gestational age } \\
\text { Weight } \\
\text { Height } \\
\text { Head circumference } \\
\text { Apgar score }\left(5^{\prime}, 10^{\prime}\right) \\
\text { Type of delivery } \\
\text { Congenital birth defects }\end{array}$ & $\begin{array}{l}\text { Clinical } \\
\text { evaluation }\end{array}$ \\
\hline 6 months & $\begin{array}{l}\text { Anthropometric child data } \\
\text { Respiratory diseases } \\
\text { - Allergic diseases } \\
\text { - Viral infections } \\
\text { - Hospitalisation } \\
\text { - CAT/CLAMS part } 1\end{array}$ & Self-reported \\
\hline 12 months & $\begin{array}{l}\text { Anthropometric child data } \\
\text { Respiratory diseases } \\
\text { Allergic diseases } \\
\text { - Viral infections } \\
\text { Hospitalisation } \\
\text { Accidents } \\
\text { - Sleep quality } \\
\text { CAT/CLAMS part } 2\end{array}$ & Self-reported \\
\hline 24 months & $\begin{array}{l}\text { Anthropometrics child } \\
\text { data } \\
\text { Respiratory diseases } \\
\text { - Allergic diseases } \\
\text { Viral infections } \\
\text { - Hospitalisation } \\
\text { - Incidents } \\
\text { - Sleep quality } \\
\text { - Barkley's scale of infant } \\
\text { development }\end{array}$ & $\begin{array}{l}\text { Clinical } \\
\text { evaluation }\end{array}$ \\
\hline
\end{tabular}

cadmium levels $>0.30 \mu \mathrm{g} / \mathrm{L} .{ }^{44}$ From these data, we estimate that a sample of 129 subjects for each study and control area (258 subjects as total sample) will be adequate for detecting such differences in 5-min Apgar scores, with an alpha level of 0.05 and a power (1- $\beta$ ) of 0.95 .

\section{Aims}

NEHO is the first cohort in Italy to study and analyse pollutant blood levels in pregnant women living near highly polluted areas along with fetal exposure. The project will attempt to identify the influence of environmental risk factors for placental function, pregnancy outcomes and newborns' health outcomes.

Finally, NEHO will enrol mother-child pairs residing in disadvantaged areas with low socioeconomic status, thus representing a particular condition in the context of Italian and European birth cohorts.

Thus, on the basis of the collected data, the NEHO cohort is aimed at the following:

- Evaluating the risk of heavy metals and emerging contaminants during pregnancy in a cohort of mother-child pairs residing in highly polluted areas 
characterised by different levels of environmental pollution.

- Evaluating the bioaccumulation features and patterns of toxicants by examining their distribution in maternal, placental and fetal tissues.

- Determining whether the bioaccumulation of toxicants might impact placental mRNA expression.

- Understanding whether prenatal exposure to contaminants may cause negative pregnancy outcomes and/ or long-term effects on children's health and disease susceptibility.

- Defining the associations of placental contamination and gene expression patterns with long-term infant health outcomes, to evaluate the validity of placental analyses in predicting future infant health outcomes.

\section{Patient and public involvement}

The recruitment is based on healthy pregnant volunteers. Patients and the public were neither involved in the study design nor in the establishment of questions and/or outcome definition. No individual results will be provided to participants unless there is a possible impact on their health.

\section{Ethics and dissemination}

The collection of human tissues and the creation of a biobank for medical research involve important ethical and legal issues ${ }^{45}$; consequently, a complete explanation of the details and the aims of the research project to participants is a prerequisite for enrolment. To promote and guarantee respect for pregnant women's free choice, during a routine visit, pregnant women receive a great deal of information about the collection and storage of biological samples until the child turns 18 . The participants are required to sign a consent form confirming their complete understanding of the project's scope and indicating their agreement to take part in the project. This includes knowing how to withdraw from the project at any time if they change their mind.

Qualified project staff (biologists, midwives, nurses, gynaecologists) provide complete information about the project and manage the completion of the baseline questionnaire and the collection of blood samples. Aimed at making data totally comparable with previous large Italian birth cohorts, the questionnaire was developed from the Piccolipiù questionnaire. ${ }^{14}$

After completing the questionnaire, a unique identification code is automatically assigned to each woman to identify the questionnaires and the biological samples collected during the study, preserving complete pseudonymisation. The study is being conducted following the Declaration of Helsinki. All the adopted procedures comply with the General Data Protection Regulation (UE 2016/679) and Italian laws concerning data protection.

The results of the study will be communicated to participants, the local Regional Health Authorities and clinical professionals only on an aggregated basis through ad hoc meetings. The researchers will also disseminate results by means of peer-reviewed journals and scientific conferences.

\section{Author affiliations}

${ }^{1}$ National Research Council of Italy, Institute of Biomedicine and Molecular Immunology, Palermo, Italy

${ }^{2}$ P.O. 'Fogliani', Local Health Authority (ASP) of Messina, Milazzo (ME), Italy ${ }^{3}$ P.O. 'Umberto I', Local Health Authority (ASP) of Siracusa, Siracusa, Italy ${ }^{4}$ P.O. 'San Giovanni di Dio', Local Health Authority (ASP) of Crotone, Crotone, Italy ${ }^{5}$ P.O. di Lentini, Local Health Authority (ASP) of Siracusa, Lentini (SR), Italy ${ }^{6}$ ASP Siracusa, Local Health Authority (ASP) of Siracusa, Siracusa, Italy

Acknowledgements We wish to thank the colleagues involved in the Piccolipiù birth cohort for their support in defining questionnaires and the structure of the study. In particular, the present work has been carried out as part of a scientific collaboration among the National Research Council of Italy-Institute of Biomedicine and Molecular Immunology, Palermo, the Department of Epidemiology, LazioRegional Health System, Rome, and the Unit of Epidemiology, 'Anna Meyer' Children's University Hospital, Florence. We also thank Dr Palma Audino for her effective support in defining tests for physiological and behavioral development.

Contributors SR, GD, PC and FC made substantial contributions to the conceptualisation and design of the study and are involved in study monitoring. They drafted and critically revised the manuscript for its intellectual content, gave final approval of the version to be published and agreed to be accountable for all aspects of the work. AA, PA, ABi, ABu, PD, RDS, VLR, AL, LLP, BM, FP, GP and AZC made substantial contributions to data acquisition and were involved in drafting the manuscript. Each of the authors read and approved the final version of the manuscript.

Funding The CISAS project is a multidisciplinary project on environment/health relationships funded by the Italian Ministry of Education, Universities and Research (MIUR) and approved by the Interministerial Committee for Economic Planning (CIPE) — body of the Italian government-with Resolution no. 105/2015 of 23 December 2015.

Map disclaimer The depiction of boundaries on the map(s) in this article do not imply the expression of any opinion whatsoever on the part of BMJ (or any member of its group) concerning the legal status of any country, territory, jurisdiction or area or of its authorities. The map(s) are provided without any warranty of any kind, either express or implied.

\section{Competing interests None declared.}

Patient consent for publication Not required.

Ethics approval The NEHO study protocol has been approved by the Ethics Committees responsible for the three involved NPCSs: the Ethics Committee of the University Hospitals of Messina for the NPCS of Milazzo-Valle del Mela (18 September 2017, n. 9/2017); the Ethics Committee 'Catania 2' for the NPCS of Augusta-Priolo (11 July 2017, n. 38/2017/CECT2); the Ethics Committee of the Region of Calabria for the NPCS of Crotone (20 July 2017, n. 173). Each participant read the information sheet and signed the informed consent. Copies of participants' information sheets are available at the website (www.neho.it).

Provenance and peer review Not commissioned; externally peer reviewed.

Open access This is an open access article distributed in accordance with the Creative Commons Attribution Non Commercial (CC BY-NC 4.0) license, which permits others to distribute, remix, adapt, build upon this work non-commercially, and license their derivative works on different terms, provided the original work is properly cited, appropriate credit is given, any changes made indicated, and the use is non-commercial. See: http://creativecommons.org/licenses/by-nc/4.0/.

\section{REFERENCES}

1. Fleming TP, Watkins AJ, Velazquez MA, et al. Origins of lifetime health around the time of conception: causes and consequences. Lancet 2018;391:1842-52.

2. World Health Organization. The European health report 2005: public health action for healthier children and populations: WHO Regional Office for Europe, 2005.

3. Barker DJ, Osmond C, Winter PD, et al. Weight in infancy and death from ischaemic heart disease. Lancet 1989.

4. Barker DJ. The fetal and infant origins of adult disease. BMJ 1990;301:1111. 
5. Barker DJP. Maternal nutrition, fetal nutrition, and disease in later life. Nutrition 1997;13:807-13.

6. Barker DJ. The developmental origins of adult disease. J Am Coll Nutr 2004;23:588S-95.

7. Barker DJ. The origins of the developmental origins theory. $J$ Intern Med 2007;261:412-7.

8. Gluckman P, Hanson M. Developmental Origins of Health and Disease: Cambridge University Press, 2006.

9. Kordas K, Park A. European birth cohorts offer insights on environmental factors affecting human development and health. Int $J$ Epidemiol 2015;44:731-4.

10. Richiardi L, Baussano I, Vizzini L, et al. Feasibility of recruiting a birth cohort through the Internet: the experience of the NINFEA cohort. Eur J Epidemiol 2007;22:831-7.

11. Vecchi Brumatti L, Montico M, Russian S, et al. Analysis of motivations that lead women to participate (or not) in a newborn cohort study. BMC Pediatr 2013;13:53.

12. Brescianini $\mathrm{S}$, Fagnani $\mathrm{C}$, Toccaceli $\mathrm{V}$, et al. An update on the Italian Twin Register: advances in cohort recruitment, project building and network development. Twin Res Hum Genet 2013;16:190-6.

13. Farchi $\mathrm{S}$, Forastiere $\mathrm{F}$, Vecchi Brumatti $\mathrm{L}$, et al. Piccolipiù, a multicenter birth cohort in Italy: protocol of the study. BMC Pediatr 2014:14:36.

14. Porta D, Fantini MP. Prospective cohort studies of newborns in Italy to evaluate the role of environmental and genetic characteristics on common childhood disorders. Ital J Pediatr 2006.

15. Barchitta M, Maugeri A, La Rosa MC, et al. Single Nucleotide Polymorphisms in Vitamin D Receptor gene affect birth weight and the risk of preterm birth: results from the "Mamma \& Bambino" Cohort and a meta-analysis. Nutrients 2018;10:1172.

16. Vizcaino E, Grimalt JO, Fernández-Somoano A, et al. Transport of persistent organic pollutants across the human placenta. Environ Int 2014:65:107-15.

17. Leonetti C, Butt CM, Hoffman $\mathrm{K}$, et al. Concentrations of polybrominated diphenyl ethers (PBDEs) and 2,4,6-tribromophenol in human placental tissues. Environ Int 2016;88:23-9.

18. Jeong Y, Lee S, Kim S, et al. Placental transfer of persistent organic pollutants and feasibility using the placenta as a non-invasive biomonitoring matrix. Sci Total Environ 2018;612:1498-505.

19. Foster WG, Gregorovich S, Morrison KM, et al. Human maternal and umbilical cord blood concentrations of polybrominated diphenyl ethers. Chemosphere 2011:84:1301-9.

20. Arbuckle TE, Kubwabo C, Walker M, et al. Umbilical cord blood levels of perfluoroalkyl acids and polybrominated flame retardants. Int J Hyg Environ Health 2013;216:184-94.

21. Jones R, Golding J. Choosing the types of biological sample to collect in longitudinal birth cohort studies. Paediatr Perinat Epidemiol 2009;23:103-13.

22. Leino $\mathrm{O}$, Kiviranta $\mathrm{H}$, Karjalainen $\mathrm{AK}$, et al. Pollutant concentrations in placenta. Food Chem Toxicol 2013;54:59-69.

23. Soares MJ, Varberg KM, Iqbal K. Hemochorial placentation: development, function, and adaptations. Biol Reprod 2018;99:196-211.

24. Bruin JE, Gerstein HC, Holloway AC. Long-term consequences of fetal and neonatal nicotine exposure: a critical review. Toxicol Sci 2010;116:364-74.

25. Votavova H, Dostalova Merkerova M, Fejglova K, et al. Transcriptome alterations in maternal and fetal cells induced by tobacco smoke. Placenta 2011;32:763-70.
26. Piasek M, Mikolić A, Sekovanić A, et al. Cadmium in Placenta-A valuable biomarker of exposure during pregnancy in Biomedical Research. J Toxicol Environ Health A 2014;77:1071-4.

27. Gundacker C, Fröhlich S, Graf-Rohrmeister K, et al. Perinatal lead and mercury exposure in Austria. Sci Total Environ 2010;408:5744-9.

28. Gundacker $C$, Hengstschläger $M$. The role of the placenta in fetal exposure to heavy metals. Wien Med Wochenschr 2012;162:201-6.

29. Rylander L, Strömberg U, Hagmar L. Lowered birth weight among infants born to women with a high intake of fish contaminated with persistent organochlorine compounds. Chemosphere 2000;40:1255-62.

30. Esteban-Vasallo MD, Aragonés N, Pollan M, et al. Mercury, cadmium, and lead levels in human placenta: a systematic review. Environ Health Perspect 2012;120:1369-77.

31. Caserta D, Graziano A, Lo Monte G, et al. Heavy metals and placental fetal-maternal barrier: a mini-review on the major concerns. Eur Rev Med Pharmacol Sci 2013;17:2198-206.

32. Carere M, Musmeci L, Bianchi F, et al. Study for the environmental health characterization of the contaminated sites of Gela and Priolo. Istituto Superiore di Sanità. Rapporti ISTISAN 2016.

33. Barone V, Calenda C, Motta F, et al. Inquinamento e recupero nel crotonese. Ecoscienza 2010.

34. Comba P, Pitimada M. Epidemiological study of Calabria Region contaminated sites: aims, methods and feasibility. Istituto Superiore di Sanità. Rapporti ISTISAN 2016.

35. Pirastu R, Ancona C, lavarone I, et al. SENTIERI Project. Mortality study of residents in Italian polluted sites: evaluation of the epidemiological evidence. Epidemiol Prev 2010;34:1-2.

36. Pirastu R, lavarone I, Pasetto R, et al. SENTIERI Project - Mortality study of residents in Italian polluted sites: Results. Epidemiol Prev 2001;35:1-204

37. Gardosi J, Kady SM, McGeown P, et al. Classification of stillbirth by relevant condition at death $(\mathrm{ReCoDe})$ : population based cohort study. BMJ 2005;331:1113-7.

38. Salafia CM, Pezzullo JC, López-Zeno JA, et al. Placental pathologic features of preterm preeclampsia. Am J Obstet Gynecol 1995;173:1097-105.

39. Junaid TO, Brownbill P, Chalmers N, et al. Fetoplacental vascular alterations associated with fetal growth restriction. Placenta 2014;35:808-15.

40. Sobrevia L, Abarzúa F, Nien JK, et al. Review: Differential placental macrovascular and microvascular endothelial dysfunction in gestational diabetes. Placenta 2011;32:S159-S164.

41. Maltepe E, Fisher SJ. Placenta: the forgotten organ. Annu Rev Cell Dev Biol 2015:31:523-52.

42. Capute AJ, Accardo PJ. The infant neurodevelopmental assessment: a clinical interpretive manual for CAT-CLAMS in the first two years of life, part 1. Curr Probl Pediatr 1996;26:238-57.

43. Sorkun HC, Bir F, Akbulut M, et al. The effects of air pollution and smoking on placental cadmium, zinc concentration and metallothionein expression. Toxicology 2007;238:15-22.

44. García-Esquinas E, Pérez-Gómez B, Fernández-Navarro P, et al. Lead, mercury and cadmium in umbilical cord blood and its association with parental epidemiological variables and birth factors. BMC Public Health 2013;13:841.

45. Toccaceli V, Serino L, Stazi MA. Informed consent, and an ethico-legal framework for paediatric observational research and biobanking: the experience of an Italian birth cohort study. Cell Tissue Bank 2014;15:579-90. 